\title{
DISCOVERING THE COHESION OF A VOLLEYBALL TEAM AND FINDING THE RIGHT LEADER OF THE GROUP
}

\author{
Marcel POMOHACI \\ “Lucian Blaga” University of Sibiu, Romania \\ marcelpomohaci@yahoo.com \\ Ioan Sabin SOPA \\ "Lucian Blaga” University of Sibiu, Romania \\ sopa_sabin@yahoo.com
}

\begin{abstract}
The main focus of the research was to discover the cohesion of our team and to find the leader of our volleyball group. The research sample was composed of 12 players with aged between 10 and 12 years old that play for CSM Bucharest at mini-volleyball level. The main research methods used was the sociometric survey method which aimed to find the elections and rejections in our group and to discover the hierarchy of every player in the team.

The results showed that we had 8 mutual elections and 4 mutual rejections in our group, and an index of cohesion of 0.06 with a coefficient of cohesion of 0.12 that showed us that our volleyball team is cohesive and united, the group leaders were player SS (8) with a preferential status index of 0.67 and at the second position we find player EG (5) with a preferential status index of 0.25 .

Conclusions have shown that the research hypothesis was valid, so we can affirm that using the sociometric survey method we can determine the group cohesion and find the right leader of our group.
\end{abstract}

KEYWORDS: group cohesion, sociometric survey method, leader of the team

\section{Introduction}

Scientists discovered that group cohesion has a considerable influence on the performance and other fundamental factors in team sports life (Carron \& Eys, 2012). Regarding a theoretical definition of cohesion the majority of specialists refer to a person's social cognitions and perceptions about a group (Dion, 2000; Carron et al., 2002). Another definition of group cohesion in sport was made by Carron,
Brawley \& Widmeyer in 1998 and he defined cohesion as a dynamic process in which we can observe the tendency for the members of the sport group to stick together and stay united following their purposes for satisfaction of member affective needs. Specialists affirm that this tendency is determined by some forces that affect the members within the sport group (Dion, 2000). First of all the social attraction between members of the group: 
the degree of need for relatedness, the sense of appreciation and reciprocal acceptance of members within the group, the communion and the support between members of the group has a big influence on the level of attraction and group membership (Yalom, 2010).

Specialists in sport psychology replaced the term of cohesion with team unity and team chemistry that is the main group variable (Carron, Burke \& Shapcott, 2009). As scientists Esa Rovio and Jari Eskola affirm the definition of group cohesion is based on important concepts like task and social cohesion, as a group is often composed to obtain and fulfill an objective, task cohesion has a fundamental role in the functioning of every sport group. Social cohesion is another cohesive force developed in time among the group members.

Many scientific publications proved that between team cohesion and team success is a strong relationship. The relationship between task cohesion and team success was analyzed by many scientist and results found showed that cohesive groups have better performances (Carron et al., 2002). Others scientific studies discovered strong relationships between factors like leadership and leader of the sport group (Hardy, Eys \& Loughead, 2008; Caperchione, Mummery \& Duncan, 2011), group cohesion and collective efficacy (Heuze, Raimbault \& Fontayne, 2006) and role involvement (Eys \& Carron, 2001).

The information found in the specialty literature on leadership and sport leaders is poor compared with other related subjects on leadership in organizational settings (Crust \& Lawrence, 2006).

Some definitions about leadership made by researchers in the sport field concluded that this behavioral process influences the members of the group in the direction of proposing and then achieving goals. Leaders have dual purpose: first purpose is to provide players satisfaction and the second purpose is to offer guidance for every member of the group so that to ensure team success. Leadership is defined as " $a$ process whereby an individual influences a group of persons to achieve a common goal" (Northouse, 2010). Other definitions of leadership affirm that "leadership processes should be similar in different contexts and their success and effectiveness should rely on similar factors" (Weinberg \& McDermott, 2002).

Recent studies focused their attention on the process of leadership of coach and their influence in leading the team (Chelladurai \& Riemer, 1998). The leadership term goes further than the process of leading the group made by any coach, as well as role players can retrieve some of the leadership duties that coaches have and accomplish many leadership features (Northouse, 2010). The leadership of a role player is defined in many scientific researches as the player that fills a formal or informal role inside the team, who influences and lead the group of team members to realize and fulfill a common objective (Loughead, Hardy, \& Eys, 2006).

Studies regarding the leadership and how should a leader manifest consider as crucial characteristics of a proper leader the motivational, communicational and encouraging skills (Dupuis, Bloom, \& Loughead, 2006; Holmes, McNeil, \& Adorna, 2010; Cotterill, 2013). Some other special skills are required for a proper leader like creating socio-emotional involvement, creating friendships and having a good atmosphere inside the group and in and outside the court, not having this kind of skills can lead to a collective collapse (Apitzsch, 2009).

The leading process and choosing the right captain is a nowadays subject that many researchers are focused on (Dupuis et al., 2006; Grandzol, Perlis, \& Draina, 2010; Voelker et al., 2011), the role of the leader include also fulfilling the task and social behaviors, offering their social support and 
sometime even helping in coaching the team. Around team captain revolves all team life, players, trainers, coaches, and mass media in and off the court. Although many research had as main subject the captain of the team few of them focused their attention on the impact of the informal leadership (Loughead et al., 2006).

Another notion caught our attention recently some studies focused on the importance of characteristics of highly resilient sport teams named "shared leadership" (Morgan, Fletcher \& Sarkar, 2013). The shared leadership reinforces the idea that players within the sport team can also have high influential position and can have the informal role of leaders of the team not necessarily the captain of the team.

\section{Objectives}

The objectives of our investigation was to evaluate the group cohesion and relationships found inside our volleyball team using the sociometric survey method.

\section{Study Hypothesis}

Using the sociometric survey method we can determine the group cohesiveness and find the right leader of the team.

\section{Student Samples}

The experiment took place at the Gymnasium School Nr. 179, Sector 1 Bucharest on the mini-volleyball team of CSM Bucharest, between 1 October 2016 and 1 September 2017. The group was formed from 12 male players that activates on CSM Bucharest at mini-volleyball level (11 \pm 1.4 years old)

\section{Materials and Methods}

In our research we used as methods of scientific investigation the following materials and methods: the observation method and the experiment method; the sociometric survey method.

\section{The Sociometric Test Applied on the Volleyball Team}

The sociometric test consisted in 2 questions regarding players' preferences on team captain:

1. List the top three players that you will choose for team captain.

2. List the top three players that you would not choose for team captain.

The players' preferences for team captain received points depending on their position of election: first position +3 points, second position +2 and the third position +1 . At the second question players listed the players with fewer chances to be team captain ( -3 points first position, -2 and -1 the second and third position).

After the centralization of the results expressed by players we calculated their preferential status index and their social status index with the following formulas:

- Social status index of $\mathrm{A}$ :

$I_{S S}=\frac{N(A)}{N-1}=\frac{\sum(A)}{N-1}$,

where $\mathrm{I}_{\mathrm{sS}} \varepsilon[0,1], \quad \mathrm{N}(\mathrm{A})$ - number of subjects that choose $\mathrm{A}, \mathrm{N}$ - number of subjects

- Preferential status index of A:

$$
I_{S P}=\frac{\sum A-\sum R}{N-1}
$$

where $\mathrm{I}_{\mathrm{sp}} \varepsilon[-1,1], \quad \mathrm{A}$ - number that choose $\mathrm{A}, \mathrm{R}$ - number that rejects $\mathrm{A}$.

\section{The results of the experiment}

Calculating the preferential status index and the social status index based on the elections and rejections made

Table no. 1

The elections and rejections expressed by the volleyball players

\begin{tabular}{cccccccccc}
\hline Subjects & $+\mathbf{3}$ & $\mathbf{+ 2}$ & $\mathbf{+ 1}$ & $\mathbf{- 1}$ & $\mathbf{- 2}$ & $\mathbf{- 3}$ & $\mathbf{I}_{\mathbf{s s}}(\mathbf{1})$ & $\mathbf{I}_{\mathbf{s p}}(\mathbf{2})$ & Rank \\
\hline AN (1) & 10 & 8 & 5 & 7 & 3 & 6 & 0.08 & -0.17 & 5 \\
\hline BO (2) & 6 & 11 & 12 & 4 & 7 & 1 & 0.25 & 0.08 & 3 \\
\hline CD (3) & 8 & 5 & 10 & 2 & 4 & 9 & 0.17 & -0.25 & 6 \\
\hline
\end{tabular}




\begin{tabular}{cccccccccc}
\hline Subjects & $\mathbf{+ 3}$ & $\mathbf{+ 2}$ & $\mathbf{+ 1}$ & $\mathbf{- 1}$ & $\mathbf{- 2}$ & $\mathbf{- 3}$ & $\mathbf{I}_{\text {ss }}(\mathbf{1})$ & $\mathbf{I}_{\text {sp }}(\mathbf{2})$ & Rank \\
\hline CI (4) & 10 & 5 & 9 & 11 & 6 & 12 & 0.17 & -0.25 & 6 \\
\hline EG (5) & 2 & 8 & 6 & 10 & 7 & 1 & 0.42 & 0.25 & 2 \\
\hline PR (6) & 7 & 11 & 8 & 9 & 5 & 10 & 0.25 & -0.17 & 5 \\
\hline RA (7) & 8 & 5 & 6 & 3 & 12 & 1 & 0.08 & -0.33 & 7 \\
\hline SS (8) & 5 & 3 & 12 & 6 & 4 & 11 & 0.67 & 0.67 & 1 \\
\hline TA (9) & 4 & 5 & 8 & 3 & 2 & 7 & 0.08 & -0.17 & 5 \\
\hline TI (10) & 11 & 8 & 1 & 4 & 3 & 5 & 0.25 & 0.08 & 3 \\
\hline VI (11) & 2 & 5 & 3 & 4 & 7 & 6 & 0.25 & 0.08 & 3 \\
\hline ZM (12) & 8 & 1 & 2 & 6 & 3 & 9 & 0.17 & 0 & 4 \\
\hline
\end{tabular}

The first step in our investigation was to register and centralize the elections and rejections expressed by our players in the questionnaire in Table no. 1 . On the first column we can find the 12 players of the experimental sample with their initials and a number in brackets. On the next six columns we can see the elections and rejections expressed by the players so for example on the second raw of the table we have player no. 1 AN (1) and his elections: player no. 10 , no. 8 and no. 5 , then his rejections player no. 7, no. 3 and no. 6 .

On column 8 and 9 we calculated every player's preferential status index and social status index and on column 10 we have their rank in group. So for example player AN (1) has a social status index of 0.08 and a preferential status index of -0.17 , being ranked on the $5^{\text {th }}$ level.

\section{Socio-matrix of elections and rejections}

Table no. 2

The Socio-matrix of rejections and elections expressed by the volleyball players

\begin{tabular}{ccccccccccccc}
\hline Subjects & $\begin{array}{c}\text { AN } \\
(\mathbf{1})\end{array}$ & $\begin{array}{c}\text { BO } \\
(\mathbf{2})\end{array}$ & $\begin{array}{c}\text { CD } \\
(3)\end{array}$ & $\begin{array}{c}\text { CI } \\
(4)\end{array}$ & $\begin{array}{c}\text { EG } \\
\mathbf{( 5 )}\end{array}$ & $\begin{array}{c}\text { PR } \\
(\mathbf{6})\end{array}$ & $\begin{array}{c}\text { RA } \\
(7)\end{array}$ & $\begin{array}{c}\text { SS } \\
(8)\end{array}$ & $\begin{array}{c}\text { TA } \\
(9)\end{array}$ & $\begin{array}{c}\text { TI } \\
(\mathbf{1 0})\end{array}$ & $\begin{array}{c}\text { VI } \\
(11)\end{array}$ & $\begin{array}{c}\text { ZM } \\
(\mathbf{1 2})\end{array}$ \\
\hline AN (1) & & & -2 & & +1 & -3 & -1 & +2 & & +3 & & \\
\hline BO (2) & -3 & & & -1 & & +3 & -2 & & & & +2 & +1 \\
\hline CD (3) & & -1 & & -2 & +2 & & & +3 & -3 & +1 & & \\
\hline CI (4) & & & & & +2 & -2 & & & +1 & +3 & -1 & -3 \\
\hline EG (5) & -3 & +3 & & & & +1 & -2 & +2 & & -1 & & \\
\hline PR (6) & & & & & -2 & & +3 & +1 & -1 & -3 & +2 & \\
\hline RA (7) & -3 & & -1 & & +2 & +1 & & +3 & & & & -2 \\
\hline SS (8) & & & +2 & -2 & +3 & -1 & & & & & -3 & +1 \\
\hline TA (9) & & -2 & -1 & +3 & +2 & & -3 & +1 & & & & \\
\hline TI (10) & +1 & & -2 & -1 & -3 & & & +2 & & & +3 & \\
\hline VI (11) & & +3 & +1 & -1 & +2 & -3 & -2 & & & & & \\
\hline ZM (12) & +2 & +1 & -2 & & & -1 & & +3 & -3 & & & \\
\hline Total & 0 & 4 & -5 & -4 & 9 & -5 & -7 & 16 & -6 & 4 & 3 & -3 \\
\hline
\end{tabular}


In the Table no. 2 we can see the socio-matrix of elections and rejections expressed by every player in our volleyball team. In the first column and the first raw we can find the subjects of the investigation and their expressed choices for team captain. At the bottom of the table we can see the total amount of points received by every player. index:

Calculating the group cohesion

Mutual elections:

$$
\begin{array}{ccccc}
\mathrm{M}_{\mathrm{e}}=8 & 1-10 & 2-11 & 2-12 & 3-8 \\
4-9 & 5-8 & 6-7 & 8-12
\end{array}
$$

Mutual rejections:

$M_{r}=4 \quad 1-7 \quad 3-9 \quad 4-11 \quad 5-10$
Calculating the index of cohesion:

$\mathrm{I}_{\mathrm{c}}=\frac{2 x\left(\Sigma A_{r}-\Sigma R_{r}\right)}{N(N-1)}$

Calculating the coefficient of cohesion:

$$
C_{c}=\frac{2 \times \Sigma A_{r}}{N(N-1)} \quad \mathbf{= 0 . 1 2}
$$

The index of cohesion was 0.06 and the coefficient of cohesion was 0.12 that show us that our volleyball group is cohesive and the leaders are players SS (8) and palyer EG (5) results

The presentation of sociometric test

The sociogram of mutual elections and rejections

Type of sociogram: Target

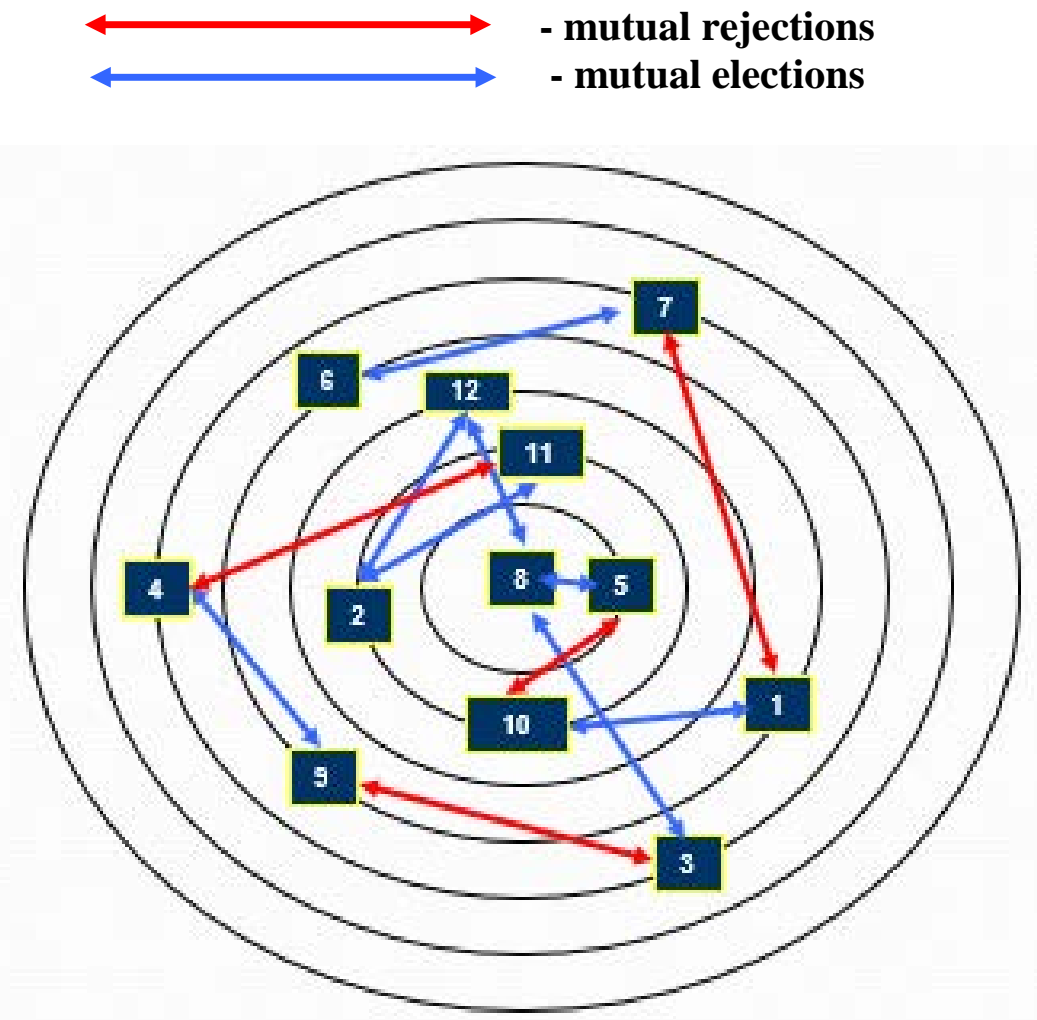

Figure no. 1: Sociogram of mutual elections and mutual rejections expressed by the players from the volleyball team

In Figure no. 1 we can see the sociogram of mutual elections and mutual rejections expressed by the players from our volleyball team. The sociogram is target type with 7 circles that are the levels that express the rank of every player. So in the center of the circle we have the leader of the team player no. 8, on second circle we have player no. 5 the second leader and so on until the last circles where we can find the rejected player. 
With the red color we can observe the 4 mutual rejections between players and with the blue color we can find the 8 mutual elections.

\section{Conclusions}

The research hypothesis was validated using the sociometric survey method we manage to identify the relationships from the sport group, the hierarchy of the group and to discover the leader of our volleyball team.
The cohesion of the sport group was good with an cohesion index of 0.06 and a coefficient of cohesion of 0.12 .

Using the sociometric method we found that the leader chosen by the sport group was player SS (8) with a preferential status of 0.67 , followed by player EG (5) with an index of 0.42 .

The elections for the two team captain made by the players was similar with the choices indicated by the coaches for the captain position.

\section{REFERENCES}

Apitzsch, E. (2009). A case study of a collapsing handball team. In S. Jern \& J. Näslund (Eds.), Dynamics Within and Outside the Lab.

Caperchione, C., Mummery, W. K., \& Duncan, M. (2011). Investigating the relationship between leader behaviours and group cohesion within women's walking groups, Journal of Science and Medicine in Sport, 14(4), 325-30.

Carron, A. V., \& Eys, M.A. (2012). Group Dynamics in Sport, 4th ed., Morgantown, WV: Fitness Information Technology.

Carron, A. V., Brawley, L. R., \& Widmeyer, W. N. (2002). The Group Environment Questionnaire test manual, Morgantown, WV: Fitness Information Technology.

Carron, A. V., Brawley, L. R., \& Widmeyer, W. N. (1998). The measurement of cohesiveness in sport groups. In Duda, J.L. (Ed.), Advances in sport and exercise psychology measurement (pp. 213-226), Morgantown, WV: Fitness Information Technology.

Carron, A. V., Burke, S. M., \& Shapcott, K. M. (2009). Enhancing team effectiveness. In Brewer, B. W. (Ed.), International Olympic Committee Medical Commission handbook of sports medicine and science, Sport psychology, Oxford: Wiley-Blackwell Publishing, Ltd.

Chelladurai, P., \& Riemer, H. A. (1998). Measurement of leadership in sport. In Duda, J. L. (Ed.), Advances in sport and exercise psychology measurement, Morgantown, WV: Fitness Information Technologies. Routledge.

Cotterill, S. (2013). Team psychology in sports: Theory and practice, Abingdon:

Crust, L., \& Lawrence, I. (2006). A review of leadership in Sport: Implications for football management, Athletic Insight, 8(4), 28-48.

Dion, K. L. (2000). Group cohesion: From "field of forces" to multidimensional construct. Group Dynamics, Theory, Research, and Practice, 4, 7-26.

Dupuis, M., Bloom, G. A., \& Loughead, T. M. (2006). Team captains' perceptions of athlete leadership, Journal of Sport Behavior, 29(1), 60-78.

Eys, M. A., \& Carron, A. V. (2001). Role ambiguity, task cohesion and task selfefficacy, Small Group Research, 32, 356-373.

Grandzol, C., Perlis, S., \& Draina, L. (2010). Leadership development of team captains in 445 collegiate varsity athletics, Journal of College Student Development, 51(4), 403-418.

Hardy, J., Eys, M. A., \& Loughead, T. M. (2008). Does communication mediate the athlete leadership to cohesion relationship?, International Journal of Sport Psychology, 39, 329-345. 
Heuze, J. P., Raimbault, N., \& Fontayne, P. (2006). Relationships between cohesion, collective efficacy and performance in professional basketball teams: an examination of mediating effects, Journal of Science and Medicine in Sport; 24(1), 59-68.

Holmes, R. M., McNeil, M., \& Adorna, P. (2010). Student athletes' perceptions of formal and informal team leaders, Journal of Sport Behavior, 33(4), 338-351.

Loughead, T. M., Hardy, J., \& Eys, M. A. (2006). The nature of athlete leadership, Journal of Sport Behavior, 29, 142-158.

Morgan, P. B. C., Fletcher, D., \& Sarkar, M. (2013). Defining and characterizing team resilience in elite sport, Psychology of Sport and Exercise, 14(4), 549-559.

Northouse, P. G. (2010). Leadership: Theory and practice, Thousand Oaks, CA: Sage Publications, Inc.

Rovio, E., Eskola, J., Kozub, S. A., Duda, J., \& Lintunen, T. (2009). Can High Group Cohesion Be Harmful? A Case Study of a Junior Ice-Hockey Team, Small Group Research Sage Publications, 40(4), 421-435.

Voelker, D. K., Gould, D., \& Crawford, M. J. (2011). Understanding the experience of high school sport captains, The Sport Psychologist, 25(1), 47-66.

Weinberg, R., \& McDermott, M. (2002). A comparative analysis of sport and business organizations: Factors perceived critical for organizational success, Journal of Applied Sport Psychology, 14(4), 282-298.

Yalom, I. D. (2010). Theory and practical implications in group psychotherapy: A text book, Stuttgart: Klett-Cotta. 